\title{
Scientific Communication and the Nature of Science
}

\author{
Kristian H. Nielsen
}

(C) Springer Science+Business Media B.V. 2012

\begin{abstract}
Communication is an important part of scientific practice and, arguably, may be seen as constitutive to scientific knowledge. Yet, often scientific communication gets cursory treatment in science studies as well as in science education. In Nature of Science (NOS), for example, communication is rarely mentioned explicitly, even though, as will be argued in this paper, scientific communication could be treated as a central component of NOS. Like other forms of communication, scientific communication is socially and symbolically differentiated. Among other things, it encompasses technical language and grammar, lab communications, and peer reviews, all of which will be treated in this paper in an attempt to engage on an empirical and theoretical level with science as communication. Seeing science as a form of communicative action supplements the epistemological view of science that is standard to both NOS and the philosophy of science. Additions to the seven NOS aspects on Lederman's (Handbook of research on science education. Lawrence Erlbaum, Mahwah, pp. 831-879, 2007) list are put forward as well as preliminary thoughts on the inclusion of scientific communication into NOS instruction.
\end{abstract}

\section{Introduction}

Of all affairs, communication is the most wonderful. That things should be able to pass from the plane of external pushing and pulling to that of revealing themselves to man, and thereby to themselves; and that the fruit of communication should be participation, sharing, is a wonder by the side of which transubstantiation pales (Dewey 1925, p. 138).

Those engaged in the pursuit and preservation of scientific knowledge are part of a great and lasting enterprise. (...) It is unfortunate that the uninitiated cannot fully perceive the beauty of the structure, the intricacy and subtlety with which it is tied together, or the solidity of the foundations on which it is built. (...) The key element in the building and preservation of this marvelous edifice is communication. Without communication there would be no science (Abelson 1980, p. 60).

K. H. Nielsen (西)

Centre for Science Studies, Aarhus University, Ny Munkegade 120, 1520, 8000 Aarhus C, Denmark e-mail: khn@ivs.au.dk 
Despite lasting problems with defining precisely what science is, there seems to be a broad consensus within the field of science education on what aspects of the Nature of Science (NOS) should be taught in schools. NOS studies, typically, take an epistemological approach to science. Lederman (2007), in a review of the past, present, and future of NOS, written for the Handbook on Research on Science Education, defines science as a body of knowledge, a set of methods, and way of knowing. Other NOS studies, despite differences in emphasis and methodology, and despite the fact that they reach somewhat different conclusions with respect to classroom interventions, also proceed from a view of science as an epistemic endeavor. ${ }^{1}$ The epistemological viewpoint has roots in science studies. To take a highly influential example, Thomas Kuhn, in The Structure of Scientific Revolutions, saw science as "the constellation of facts, theories, and methods collected in current texts" (Kuhn 1962, p. 1), a view resembling that of Lederman (2007). Though Kuhn's work sparked a still-growing interest in social studies of science, with increasing importance given to practices, contexts, and communication, the majority of post-Kuhnian science studies have maintained focus on epistemological issues that has to do with science as (a) way(s) of knowing.

At the core of this paper is an attempt to supplement the epistemological view of science with a communicative approach to science: The sciences as configurations of modes of communication. Also, the paper provides suggestions on the implementation in NOS instruction of this supplementary view of science. The ultimate goal is include into science education the sense of wonder about communication hinted at in the Dewey quote above, as well as the fundamental role of communication in science suggested by the Abelson quotation. In what follows, based on a limited selection of others' efforts to combine science studies with communication studies, I draw out what I consider to be central communicative aspects of science. To clarify my position, I am arguing that the NOS studies may benefit from adding the perspective of communication to that of epistemology, and not that communication entirely replaces epistemology. In reference to the above Kuhn quote, I aim to draw attention on the role of communication for the ways in which facts, theories, and methods are collected "in current texts", that is, communication as a resource for making, keeping, and extending knowledge. In the final section of the paper, I also make the claim that the communicative dimensions of science are well-suited for teaching NOS.

My interest in science as a form of communication originally springs from research into science communication and popular science where the epistemological perspective on science sometimes clashes with the practice, experience, and ideology of science communication. When science is defined merely as knowledge and methods, communicating science in non-scientific forums becomes simply a matter of explaining scientific knowledge/methods in everyday language. As scholars from the field of Public Understanding of Science have argued, this linear model of knowledge dissemination (the derogative term is "the deficit model") provides a somewhat limited understanding of processes of science communication. $^{2}$ Among other things, it presupposes (and imposes) a cognitive gap between science and the public, which is counterproductive to participatory modes of interaction between scientists and lay people. Knowledge transfer no doubt is part of what science communication is all about, but there is much more to it. Science communication is

\footnotetext{
${ }^{1}$ Exemplary NOS studies are Abd-El-Khalick et al. (1998), Abd-El-Khalick and Lederman (2000), McComas (1998) and Osborne et al. (2003).

2 Public Understanding of Science studies include Bauer et al. (2007), Bensaude-Vincent (2009), Bucchi (2008), Gregory and Miller (1998) and Irwin and Wynne (1996).
} 
not only about connecting different ways of understanding the world, i.e., technical expertise versus lay knowledge or common sense, just as science education is not only about making a connection between scientific knowledge and young minds. This is not the place to go into contemporary discussions about the nature of science communication and popularization; it suffices to say that seeing science merely as knowledge and method is part of the problem of coming to a fuller understanding of the communicative practices that constitute science and other forms of communication, respectively.

\section{Adding Communication to NOS}

The epistemological approach to NOS generally refers to the relationship between scientific methods and scientific knowledge. Whereas inquiry-based science education adopts for purposes of science learning the diverse ways in which scientists study the natural world, NOS provides an opportunity for science learners to reflect upon the epistemological implications of inquiry-based knowledge. If we do not allow for intermediary processes to take place, the movement from inquiry to knowledge takes on the puzzling appearance of a leap from the particular and local to the universal and global. In the sciences, there are many different ways of inquiring about the world. According to science studies, ways of inquiry are wholly situated and embedded in history and epistemic cultures. ${ }^{3}$ So, if the making of knowledge takes place in bounded settings, and if processes of inquiry differ from, say, one discipline to another, or, from one lab to another, then how is it that scientific knowledge is able to claim objective and universal application?

Sociologist of science Steven Shapin, in a 1995 review of the sociology of scientific knowledge, put it this way:

If, as empirical research securely establishes, science is a local product, how does it travel with what seems to be unique efficiency? One appeal of the modernist grand narratives of reason, reality, and method was the table-thumbing response they offered to questions about the travel of science. If, however, universality can no longer be accepted as an assumption flowing from the very nature of knowledge or the "method" for making it, then what are the mundane means that so powerfully effect the circulation of science? (Shapin 1995, p. 307)

Shapin pointed to the actor-network theory (ANT) of Bruno Latour, Michel Callon and others as "one particularly well-developed framework for engaging with the problem of travel" (Shapin 1995, p. 307). The solution offered by ANT revolves around mobilization, mediation, and metrology. In order to travel from one context to another, scientific knowledge needs a mediator, that is, it has to be embodied in some kind of material, be it texts, specimens, instruments, etc. These materials can be mobilized or transported only insofar as they are supported by regulated infrastructures that more or less stabilize the meaning of the knowledge that is being mediated. Metrology, then, becomes central to scientific practice. Developing standards of knowledge-making and knowledge-circulation, and implementing such standards in local settings, is the sine qua non for the rise and dissemination of science as a modern institution. The tending-to-universality of scientific methods and knowledge, indeed, the strong relationships between methods and knowledge, are rooted in mundane, situated, and (increasingly) networked practices of establishing agreement with respect to standards, systems, and instrumentation (Latour 1987; Latour and Woolgar 1986).

\footnotetext{
${ }^{3}$ See for example Galison (1997), Knorr-Cetina (1999), Bruno Latour (1999b) and Shapin (2008, 2010).
} 
Historian of science James Secord (2004) took a related approach to the question of "knowledge travel" in his 2004 keynote address to the three societies of science history, the British Society for the History of Science, the Canadian Society of the History of Science, and the History of Science Society, namely that of communication. Recognizing that the problem of the movement of local knowledge is central to historical and social studies of science, Secord advised fellow historians of science to shift their focus from situated scientific practices and, instead, "think about knowledge-making itself as a form of communicative action" (Secord 2004, p. 661). As Secord noted, there are good precedents for taking such a view. The ANT approach to knowledge-in-circulation is one option, seldom fully recognized by historians of science, science educators, or even science communication scholars; another one is the contemporary strand within the philosophy of science that attaches importance to interactional dimensions of epistemology. ${ }^{4}$ Questions of trust, testimony, and communitarian knowledge pertain to the very heart of the matter: Science fundamentally is a shared form of knowledge, and conventional ways of communicating among peers and across epistemic boundaries are central to the collective and collaborative character of science.

Science, it should be noted, not only is collective and collaborative, but also highly competitive. Scientific communication, early sociologists of science such as Pierre Bourdieu (1975), Warren O. Hagstrom (1965), Robert Merton (1973) and Derek de Solla Price (1963) noted, is closely related to scientific competition. Scientists contend for recognition. Among the highest forms of recognition rank publication and citation, both of which form part of the communicative structure of science. From this perspective, scientists offer information in exchange of recognition. Recognition lends quality to scientific communication, and communication is a medium of appreciation amongst scientists. Competition and communication thus are mutually constitutive: Without competition, there would be no (or much less) scientific communication, simply because there would be no commonly accepted or standardized way of measuring the value of communication; without communication, scientific competition simply would have no medium of exchange. Arguably, due to increased competition in science and the commercialization of academic research, the norms and structures of scientific communication may be undergoing rapid transformation (Mirowski and Sent 2007; Radder 2010).

Building on science studies, NOS incorporates a view of science as a human, social enterprise. However, the acceptance of insights provided by science studies has meant that NOS, unknowingly, also has adopted the "travel" problem identified by Secord (2004) and Shapin (1995). In NOS studies, this is most evident in discussions about the tentativeness of science. Many NOS scholars agree that scientific knowledge is tentative, although there also is some uneasiness about the notion of tentativeness being too flimsy and uncertain to describe scientific knowledge (Abd-El-Khalick 2005; Lederman 2007; Osborne et al. 2003). Lederman, in particular, argues that the tentative nature of science results not only from the cultural and social embeddedness of science, but also simply because science changes "as new evidence, made possible through advances in theory and technology, is brought to bear on existing theories or laws, or as old evidence is reinterpreted in the light of new theoretical advances of shifts in the directions of established research programs" (Lederman 2007, p. 834, italics in original). Tentativeness in NOS is related to the interpretation and extension of tentative scientific knowledge and, thus, resembles the "travel" problem in science studies.

\footnotetext{
${ }^{4}$ See for example Coady (1992), Hardwig (1991), Kusch (2002) and Whyte and Crease (2010).
} 
Science is tentative, partly because it is situated in communities of practice and culture, and partly because it, like all other human enterprises, is contingent upon history. Given these aspects of science's epistemic tentativeness, how, students might ask, is it that some instances of scientific knowledge are relatively robust to changes in social and historical context? Latour's answer is this: Scientific knowledge depends crucially on time, instruments, people, and institutions; they are the "very stuff" of knowledge, that is, "the only way that exists to lay down the continuous path allowing for ideas to become loaded with enough intersections to decide retroactively if they have been correct or not" (Latour 2008, p. 98, italics in original). In a less speculative manner, and with an eye to the processes, rather than the nature of science, Secord (2004) points us in a slightly different direction, to look at science as communicative action.

Following Secord (2004), I suggest rephrasing the question of science's tentativeness in terms of communicability. Communicative practices within the sciences are highly diverse, allowing knowledge to emerge, circulate, and to be interpreted and extended (or not) within scientific communities across time and place. Indeed, the very existence of scientific knowledge presupposes communication amongst scientists. Scientific knowledge exists in networks of communication that sustain certain types of meaning and enable certain processes of communication to go on (and others to come to an end). Scientific knowledge, then, fundamentally is tentative, but only because its future applicability crucially depends on the continuation of scientific communication. The meaning of scientific knowledge is not only established by its internal qualities or the method by which it has been produced, it also depends on what other scientists make of it, that is, how scientific knowledge is being communicated. So, it's not that tentativeness suggests deficiency in scientific knowledge; rather, tentativeness is foundational to science simply because science is an ongoing process of communication in which certain forms of meaning become stable and durable, while others, temporarily, or for good, vanish. Duschl and Grandy (2008) made a somewhat similar suggestion in their attempt at rearticulating tentativeness as responsiveness (Duschl and Grandy 2008, p. 10). I want to argue that supplementing the epistemological take on NOS with scientific communication helps us understands crucial features of the practice and knowledge of science.

\section{Perspectives on Scientific Communication}

In the following sections, I will be looking at specific instances of scientific communication. Drawing on studies of the role of communication in the sciences, I use different media of communication as a heuristic tool of organization. In an attempt to cover as many different perspectives on scientific communication as possible within the framework of this paper, I take up studies of scientific language and rhetoric, lab talk, and peer reviews.

\subsection{Science's Socio-Semiotics: Language and Rhetoric}

Science, among other things, is a socio-semiotic activity: It aims at making meaning by means of signs, and it does so in social contexts and social processes. The semiotic resources of science, one has simply to engage with contemporary scientific literature to learn, are highly specialized and complex. Furthermore, they are fully embedded in the development of science as a social system of communication (Halliday 1979; Luhmann 2002). The socio-semiotic basis of science, as is the case with other social systems of communication, is semiotic codification and social structuration. Making a distinction 
between scientific knowledge and other forms of knowledge partly is based on the difference between codes of science and other forms of codification; yet, at the time, the identification and operationalization of science's codes, i.e., science's semiotic resources, or what we, using M. A. K. Halliday's (1979) concept, may think of as the "meaning potential" of science, require social contexts in which such resources or potentials are realized. In short, differentiated codification of knowledge necessitates differentiated social structures, and the development of social structures enables new meaning potentials. Social and semiotic aspects of science are "co-produced", to use a catch-phrase of contemporary science studies (Jasanoff 2004). Consequently, the notion of science as social practice, one of the basic tenets of both science studies and NOS, also feeds interest in the science's distinctive semiotic character.

In this section, I focus on studies of the language and rhetoric of science. These are two sub-areas of science studies, both of which have received relatively little attention. The latest handbook of science and technology studies, for example, contains only one chapter on argumentation in science (Keith and Rehg 2008). Keith and Rehg (2008) take a broad, implicitly socio-semiotic, approach to argumentation, their chapter treating of rhetoric, writing, controversy, institutional structures, public discourse, and policy-making. Although I fully appreciate the need to be inclusive in dealing with these issues, in the following, for reasons of brevity and consistency, I wish to limit myself to focused and empirical studies of science's language and rhetoric, respectively.

M. A. K. Halliday, J. R. Martin, and co-workers have analyzed the language of science (Halliday 2004; Halliday and Martin 1996; Martin and Veel 1998). Along the lines of the socio-semiotic basis sketched above, they break with the traditional view of scientific language as a neutral tool of observation. Language, they argue, is an enabling technology for knowledge-making. Historically, the construction of philosophical language(s) in seventeenth century Europe marked the simultaneous rise of communities of scientific practitioners (natural philosophers) and innovations in linguistics. The new language tools were utilized as "a means of arriving at new knowledge, a resource for enquiring and for thinking with" (Halliday and Martin 1996, p. 6). Scientific language, in this view, is yet another instrument, alongside other instruments, that enables (some parts of) scientific knowledge, while also performing (some parts of) social action. Like other languages for special purposes, the language of science makes possible the transformation of experience into meaning; unlike most other such languages, science systematically makes use of the transformative power of certain linguistic elements in the making of new structures of meaning, some of which are loosely coupled to experience.

Halliday and Martin identify "technical taxonomies" and "technical grammar" as the two most important linguistic resources in the language of science (Halliday and Martin 1996, p. 6). All natural languages employ ethno-taxonomies, but they all have come into being in rather messy and complex ways, at least when one compares them to the ethnotaxonomy of science originating from the work of seventeenth century natural philosophers. The language of science as it was then emerging embodied systematic and controlled taxonomies that could be used not only to observe and describe natural phenomenon in new ways, but also to facilitate more abstract kinds of knowledge about the natural world, such as second-order technical taxonomies of technical taxonomies, and importantly, knowledge about knowledge-making itself. Since then, the systematic uses of the taxonomic resources of language in science have spawned a vast number of technical terms and taxonomic hierarchies, resulting in the ever-increasing differentiation of linguistic means of construing experience that we, today, recognize as one of the defining aspects of science. 
Like technical taxonomy, the notion of technical grammar describes linguistic processes by which new scientific knowledge is being made. Grammar, in Halliday's usage, takes on a special meaning. Grammar is the system of language, but also describes its functional dimensions: In particular, grammar is a theory of human experience, that is, the grammatical function of language is the shaping of experience into communicable information and meaning. In other words, the grammar of language decides which experiences can be communicated in what ways. Grammar, moreover, can be generative. The grammar of scientific language, for example, allows scientists to construe observations in ways that permit new kinds of experience and knowledge to emerge. Halliday refers to this process as "regrammaticizing experience as technical knowledge" (Halliday 2004, p. 49). The best example is nominalization. Nominalization occurs whenever verbs, adjectives or adverbs are used as nouns or noun phrases. Transforming processes or qualities into nouns enables abstract thinking about new sematic relationships, which again can be nominalized and so on. It allows causal relationships between complex nominal groups to be conceptualized. An example? The regrammatization of experience as technical knowledge leads to an expansion of meaning and communication in the sciences. Since grammatical transformations, what Halliday calls grammatical metaphors, can go on (almost) indefinitely, they lend considerable expansive semiotic power to the language of science. To use another phrase of Halliday's, grammar is "semogenic"; it facilitates the emergence of new meaning-structures (Halliday 2004, pp. 61-63).

Besides semogenic power, linguistic resources also have rhetorical significance in science. Among other things, scientific practice is, to varying degrees, aimed at persuasion. If we accept that all knowledge is somehow shared, and that knowledge-making requires participation and collaboration, in short, if knowledge demands communication, we also need to acknowledge the role of rhetoric in facilitating knowledge communication. Scientists simply need to convince their colleagues and others of the correctness and soundness of their research; they need, for instance, to convey that their research is based on accepted methods, and that their results are trustworthy. Thomas Kuhn, in the postscript to Structure, pointed to the crucial role of persuasion in science. He noticed that whenever there is a "communication breakdown" in science, i.e., what was originally referred to as situations of incommensurability, the participants interpret differently certain experimental records or observational circumstances. Since, at best, communication between the participants is only partial, "each party must try, by persuasion, to convert the other" (Kuhn 1970, pp. 198-204, quote on p. 198). Kuhn himself attributed little, if any, weight to the rhetoric of science in processes of persuasion, but propounded the view that scientists had "good reasons for being persuaded" (Kuhn 1962, p. 199). Studies of the rhetoric of science have since then placed persuasion in a much more central position when it comes to communication of scientific knowledge. ${ }^{5}$

I would like to point to one study in particular, namely that of historian of science Steven Shapin on the literary technology of experimental science in the seventeenth century (Shapin 1984). Interestingly, Halliday (2004), Gross (1990, pp. 111-128) and Shapin (1984) all identify new techniques of communication that shaped science in the formative period of the first scientific revolution (see also Shapin 1996). Whereas Halliday analyses Newton's and Priestly's inventive usage of grammatical metaphors (Halliday 2004, pp. 140-158), and Gross notes Descartes' and Newton's diverse rhetorical strategies (Gross 1990, pp. 109-128), Shapin looks at the invention of the experimental report in Restoration England (Shapin 1984). Like Halliday (1979, 2004), Shapin argues that

${ }^{5}$ See for example Bazerman (1988), Gross (1990, 2006), Gross et al. (2002) and Myers (1990). 
"speech about natural reality is a means of generating knowledge about reality" (Shapin 1984, p. 481). The material used by Shapin to address this issue is Robert Boyle's experiments in pneumatics in the late 1650s and early 1660s. Boyle not only was an able experimenter, but also had to deal with the question of how to authenticate his experimental claims in the face of competing programs of knowledge-making. Boyle's novel strategy was to secure assent by way of experimental matters of fact. Before circa 1660 , reliable knowledge almost exclusively was logical and mathematical in kind. It required rational certainty. Boyle, therefore, had to invent a new category of knowledge based on a high degree of probability: "The fact was the item of knowledge about which it was legitimate to be 'morally certain"” (Shapin 1984, p. 483).

In order to establish moral certainty about facts, Boyle devised three new technologies: The material technology embedded in his air-pump, the social technology laying down conventions for observing and reporting on air-pump phenomena, and the "literary technology" by means of which the observations could be communicated to others. All technologies had to be reliable in order to certify the knowledge produced in Boyle's "lab". The literary technology, which to our purposes serves as the most important of Boyle's inventions, consisted of visual and narrative elements, which together performed what Shapin calls "virtual witnessing” (Shapin 1984, pp. 490-497). In Boyle's texts, visual representations were few, but comprehensive, adding a realistic quality to the textual description of the experiments. The images showed many details of the apparatus in use, facilitating the reader's taking on trust that the experiments really happened as described. Moreover, Boyle's idea about the proper "experimental essay" combined visual "prolixity" with a modest, humble and a-theoretical narrative. The style, needless to say, was "plain, puritanical, unadorned (yet convoluted)". Consequently, the experimental account, in contrast to the more speculative system of natural philosophy, first and foremost was functional: It displayed the author's intentions to serve the community of experimentalists rather than personal renown. The experimental account inscribed this (proto-scientific) community as virtual witnesses in the experiment, thereby attempting to construe the experimental results as collective matters of fact. Boyle's literary technology was made necessary by the fact that it was with the scientific community and its subsequent communications that ultimately the reliability of experimental knowledge rested.

\subsection{Lab Communication: Who's Talking?}

That communicating scientific knowledge in texts is part and parcel of scientific practice should be rather uncontroversial, but how deep into the very epistemological foundations of science does communication reach? In the above, it has been argued that knowledge is not a commodity or object that simply needs a nice wrapping. The (re)presentation of knowledge goes hand in hand with the making of knowledge. Language can be used to communicate knowledge, but also as a tool of knowledge-making. The same goes for rhetoric, broadly understood as literary technologies that constitute matters of facts. Scientific communication, however, includes much more than published texts (and much more than what is covered by this paper). In this section, I turn to experimental "shop talk", that is, the kind of communication that takes place at the heart of scientific knowledge-making, in the lab.

Imagine yourself in the lab, listening to scientists talking about their instruments and the results they produce. Unless you yourself were a skilled scientist, you probably would have a hard time following their conversation. Nevertheless, you would be able to make sense of the setting as some people at work. It certainly would be hard to identify which aspects of 
their shop talk would classify as scientific and which as non-scientific. You would have to conclude either that all of the conversation is, in some sense, scientific, or that nothing scientific is going on. Or, you might reach the conclusion, as did Lynch (1985) in his ethnomethodological account of daily life in a neurobiological laboratory, that shop talk and scientific results are co-constitutive. He argued that the discovery of substantive neurobiological facts was closely linked to ways of talking amongst neurobiologists. Agreement about the objective features of objects was reached through a communicative process of "talking science" in which neurobiologists aligned their interpretations of what was going on in the lab. One important aspect of the shop talk reported by Lynch was the identification of artifacts, where the neurobiologists came to a mutual understanding of certain features of their lab work as having nothing to do the objects under study. Artifacts were linked to improper lab conduct and/or instrumental error, facts to proper lab conduct and experimental evidence. "Talking science", then, is the establishment of scientific facts (and non-scientific artifacts) as an ongoing, interactional accomplishment of lab workers, that is, in the words of Lynch, "an integral part of the ordinary work of doing science; talking science is talk which is directly part of the collaborative achievement of inquiry" (Lynch 1985, p. 155).

Gilbert and Mulkay (1984), in their study of scientific discourse within biochemistry, also noted the asymmetrical structure of accounting of error. They distinguished between two types of interpretative repertoires that are available to scientists as they talk about scientific practice and knowledge. Both repertoires make explicit inferences from practice to knowledge: The empiricist repertoire, usually deployed in published texts, portrays scientific practice "as following unproblematically and inescapably from the empirical characteristics of an impersonal world" (Gilbert and Mulkay 1984, p. 56). The contingent repertoire rarely is used in public; it serves the purpose of making sense of errors, or artifacts. The contingent repertoire poses a close relationship between social action in the lab and the results obtained. Although it can be very flexible, it generally depicts scientific lab work "no longer as generic responses to the realities of the natural world, but as the activities and judgments of specific individuals acting on the basis of their personal inclinations and particular social positions" (Gilbert and Mulkay 1984, p. 57).

Close-up, scientific talk resembles other kinds of shop talk; scientists at work resemble other people at work, trying to accomplish proper conduct within their line of work. What, then, happens to the specific characteristics of science? Is "talking science" just another like any other shop talk, or is there something special about the ways in which scientists communicate with each other? Lynch argued that the specificity of science is closely related to the extension of shop talk:

Science is perhaps unique as an occupation for the way in which its shop work is made extensively accountable in written reports, and examined for its rational, logical and systematically achieved 'methods' as formulated in those accounts (Lynch 1985, pp. 56-57).

A similar approach to scientific communication in the lab is Latour and Woolgar's (1986) Laboratory Life. They famously depicted the laboratory as a small sign-processing factory where material objects (in this case, biomolecules) are being turned into signs, or inscriptions. The inscriptions of lab, they argued, could be traced from the lab into increasingly wider circles of communication such as published papers and peer reviews (to be discussed below). Looking at inscriptions rendered visible the role of communicative practices in the lab and the weight given by lab scientists to textual outputs. In the book, the anthropologist visiting the laboratory tries to make a connection between the scientific apparatus and the enormous amount of paperwork that piles up on the scientists' desks. He 
sees two kinds of literature being juxtaposed: The first one originates from outside the laboratory; it for the most part comprises of published articles, conference papers, etc. The other one is produced within the lab: All kinds of diagrams, tables, figures, images, rough drafts, etc. Much of this second literature has been produced by a particular kind of instruments, which Latour and Woolgar called "inscription devices" (Latour and Woolgar 1986, p. 51). These instruments transform substance into some kind of textual output, effecting a mediated and referential relation between objects and their representation. Inscription devices make possible scientific communication about objects, but also allow objects to have presence in communication (cf. the introductory quote by Dewey).

One of the functions of the laboratory is to render texts ready for publication; texts that will enter into scientific communication, ending up as the former kind of literature on some other scientist's desk in another lab. In order to enact this circular communicative structure, lab scientists engage in a dialogue with the body of scientific literature, their work being informed and guided by published texts, and aimed at the publication of new texts. The discovery of Latour and Woolgar, from the perspective of science studies, was the sociosemiotic interactions between scientists, objects and instruments. They found that scientists carefully composed their final output, the submitted research paper, combining inscriptions from laboratory instruments with references to the work of others and their own words. The notion of inscription device was intended to be "sociological"; in the words of Latour and Woolgar, "[i]t allows one to describe a whole set of occupations in the laboratory, without being disturbed by the wide variety of their material shapes" (Latour and Woolgar 1986, p. 89, note 5). In later works, Latour (1987, 1999b, 2005) has expanded on the role of materiality in social life, trying to flesh out the counterintuitive idea of lending equal agency to humans and non-humans. This attempt has sparked a lively, sometimes even aggressive debate within science studies; see for example Bloor (1999), Latour (1999a) and Pinch (2010). However, we don't have to adopt wholesale the symmetric relation between people and things to acknowledge the dynamic, flexible, and complex role of objects and instruments in scientific lab work and communication. The material world enables and resists. Objects, instruments, and the inscriptions they produce are integral parts of scientific communication. Moreover, scientific instruments necessitate collaborative communications.

The collective and heterogeneous nature of scientific communication arising in and from the lab perhaps becomes most visible when one considers different modes of scientific authorship (Biagioli and Galison 2003). The history of science provides a few instances of joint human-machine authorship. For example, in 1955, the RAND Corporation published a book called A Million Random Digits with 100,000 Normal Deviates (RAND Corporation 1955). The book has a corporate author, which is rather common. The content of the book, however, is unique. The book contains, as it is stated in the title, a million random digits and 100,000 normal deviates, all "written" by an electronic roulette wheel, specially designed electronic circuits, punch cards, and an IBM machine. Although, as is fully acknowledged in the book, the roulette wheel was designed and operated by a group of humans, the intended meaning of the array of numbers explicitly is to eliminate human bias and intention. The large table of random digits was made feasible by new developments in solving complicated distribution problems by means of Monte Carlo methods. To this end, programmers and scientists needed larger and more perfectly randomized series of digits, that is, digits arranged in non-ordered and non-biased series. Today, for randomness, researchers depend on atomic decay, atmospheric radio noise, or even Lava Lamps (Lavarnd 2011). Like the digits in the RAND book, such random figures, by definition, originate entirely from a non-human source or author; all the same, they take on definite meanings in the context of statistical science. The notion of randomness 
embodies a certain tension between human and non-human factors in the construction of scientific knowledge.

The interaction of humans, nature, and machines in the creation of scientific knowledge and communication also becomes visible when one looks at emerging modes of collective authorship with respect to the kinds of science that fundamentally build on collaborative efforts (Galison 2003). The collective author as a phenomenon is a product of big science (Galison and Hevly 1992). It emerges from the kind of scientific practice that involves not only many people and large machines, but also multi-institutional and multinational scientific collaborations. From it grew protocols of authorship with functional and contributory designations of author(s). The author is not the individual "I", but the collective "we" who may be composed in many different ways (Galison 2003). Regulating scientific authorship provides a means of securing unity and coherence inside the collaboration; it serves as a means of determining the origin of the results; and it lends credibility and reliability to scientific knowledge.

Whereas protocols of scientific authorship provide context and authority to communications emerging from big scientific collaborations, other developments tend to make scientific practice and thus scientific communication in lab-like conditions even more distributed. Galison (2003) mentions "mobile agents", that is, self-propelling computer codes that are capable of leaping from one computer system to another. Mobile agents are used to enable distributed systems of collaborations by rendering transparent to a global network of geographically and culturally dispersed scientists different kinds of instruments, protocols, and computer codes. The agents themselves have multiple authors, and they facilitate truly dispersed modes of communication between computer programs and between communities of scientists. If the collaborate "we" of the big science research paper can be described as a "pseudo-I" author, Galison suggests, then the authorship mobilized by mobile agents is a "hive-I" (Galison 2003, p. 348).

In effect, Galison (2003) raises the question of which authors, and which forms of scientific communication, are involved in the processes of making knowledge that goes in labs, or, to be more general, experimental collaborations. Authorship, or, again, more broadly, communicative performance, no longer is taken for granted. The special configuration of the large, dispersed community of physicists (and their mobile agents) provides but an example of a more general problem raised by the inclusion of communication in the making of knowledge: The tension between, on the one hand, the need to attach authorship to specific social contexts and, along with it, claims, results, and information, and, on the other hand, the distributed nature of (all kinds of) knowledge-making and authorship, is perhaps a fundamental feature of scientific knowledge. At least, this tension clearly becomes an issue in carrying out the types of collaborative efforts needed to make knowledge within high-energy physics, computational biology, climate change modeling, etc.

\subsection{Peer Reviews: Regulating Science's Communicative Efforts}

The invention of virtual witnessing, the operation of inscription devices, and the creation of protocols of collaborative authorship are important socio-semiotic resources for scientific meaning-making and for the authority of science. They all serve as both literary and social technologies that contribute to the end result of much scientific work, i.e., the submitted paper. Now, to some extent, seeing science from the viewpoint of communication implies displacing issues pertaining to standards of evaluation of scientific knowledge to those 
relating to means of communication between scientists. For example, comprehending the operation of instruments in terms of inscription, Latour and Woolgar refrain from taking a stand on the quality of inscriptions. They observe "the importance of bracketing our familiarity with the object of our study" (Latour and Woolgar 1986, p. 29). Similarly, Halliday (2004), in his linguistic analyses of Newton's and Priestly's grammatical metaphors, Shapin (1984), in highlighting Boyle's literary technology, and Galison (2003), stressing new modes of scientific authorship, all bracket discussions about the excellence of these scientists (in fact, the importance of their analyses hinges on the recognized excellence of Newton, Priestly, Boyle, and contemporary teams of high-energy physicists). These approaches, like many other science studies, exemplify the fruitfulness of replacing normative questions about science with social and semiotic ones.

Peer review most often is understood as a way of evaluating scientific work. It has a high normative standing within science and in the public, which is why studies of the limits and problems of peer review are highly challenging to the (perceived) normative structure of science. Despite (or because of) its shortcomings, some scientists therefore tend to conclude, with Guardian science writer Ben Goldacre (2009), that "peer review is flawed but the best we've got". For example, Philip Abelson, editor of Science, made the following observation about the peer review process:

The most important and effective mechanism for attaining good standards of quality in journals is the peer review system. As with any mechanism devised by humans and operated by humans, it is subject to errors and possible abuses. Such failures are often spotlighted by critics, who demand an impossible perfection without knowing how to achieve it in practice. Editors who have experienced the heavy responsibility of dealing with authors, manuscripts, reviewers, and critics are strongly supportive of the peer review system. They assert that some kind of review is essential. They say that if authors knew their manuscript would be published automatically, many would send in any kind of nonsense. The literature would become worthless, for few people would know what to give credence to (Abelson 1980, p. 62).

The availability of unrestrained electronic preprint servers and databases does not seem to invite "any kind of nonsense", such as Abelson feared, but, rather, serves to sustain certified publication patterns and/or to expand the continuum of scientific communication (Brown 2003; Gunnarsdottir 2005). We may speculate that one of the reasons why this is so is that peer review, more than a supervisory body, has other communicative functions besides control. Abelson, in the last sentence of the quote, indicates this much in saying that peer review helps people (scientists) economize the time they spent on reading other people's work. Harnad makes the same observation: Peer review serves a means of "calibrating one's finite reading time" (Harnad 1998, p. 291). The way in which this kind of scientific calibration works may be thought of as enhanced selectivity in the communication process. Peer review first of all enacts reflexivity on the part of the author(s): Does this paper that we are about to submit really live up to our joint standards of scientific communication? That this first selection has importance to scientific communicationeven without the existence of organized peer review-is witnessed by the operation and proliferation of preprint servers. Peer review, moreover, enables selectivity in the editorial and the review processes. These three levels of pre-publication selection not only narrow the choice of the scientific reader, but also ensure that all scientific papers have a minimum readership, that is, the editor(s) and reviewer(s) (the average scientific paper has less than one citation, perhaps even less than one reader, see: Harnad 1997).

There are several kinds of peer review, and, as part of the communicative infrastructure of scientific practice, it is perhaps best not to confuse them. The above comments on the communicative function of peer review are actually inspired by Hirschauer (2010) who, 
from the perspective of communication, studies editorial judgments in the peer review system of the leading German journal of sociology, Zeitschrift für Soziologie (ZfS). The peer review process of ZfS includes three steps: (1) Two external referees review the paper in detail, (2) five editors makes a summary evaluation of the paper and proposes a decision, (3) the meeting of the editors decides whether the paper should be published as it is, revised and published, revised and resubmitted, or rejected. Hirschauer makes the following two points about this procedure, both of which relate peer review to communicative action in science.

Firstly, the voting procedure includes textual and oral elements that are not easily detached from one another. In fact, Hirschauer presents voting as a communicative event interlocking speech and writing (Hirschauer 2010, p. 99, note 11). The written vote is performed in an imagined dialogue with the submitted paper and its authors, but also in the expectation of subsequent negotiations in the editorial board. Hirschauer describes the manuscript submission as an invitation to communication. By submitting their manuscript, the authors really are making two proposals: The first one concerns the scientific novelty and solidity of the paper's claims; the other one, the judgment of the authors: They claim to able to make the pre-submission judgment that their manuscript is about ready to be published. This (implicit) judgment balances the (perceived) scientific merit of ZfS and the (perceived) scientific merit of the manuscript. In their summary evaluation, the editors respond to both claims, using a number of communicative strategies. They comment on the content of the paper, and they make judgments about the authors and their judgments, usually in a "bad tempered" way, since the end result has to be "winnowing-out", rather than "hand-picking" manuscripts (Hirschauer 2010, pp. 77-78).

Secondly, more than a communicative event that involves the authors of the manuscript and its readers, the votes are directed towards the expected votes of other editors. In this respect, voting, along with the oral interactions of the editorial meeting, is a strategic intervention on behalf of editors. By voting, the editors position themselves in sociological discourse and, in so doing, make self-referential judgments about their own judgments and those of the other editors. Voting, to sum up, in the case of ZfS is much more than a simple evaluation process in which widely accepted evaluation criteria are being applied to manuscripts. In fact, the process seems to have very little to do with gatekeeping sociological knowledge by means of rational cognition. Gatekeeping, surely, is one of the functions of peer review; however, gatekeeping, a point made several years ago by the founder of ethnomethodology, is not so much the application of rules of correct decisionmaking in certain situations as the collective probing of such rules in terms of an ongoing re-enactment of the social setting in which the rules can be made meaningful (Garfinkel 1967). As Hirschauer stresses, the peer review process of ZfS has to be taken serious as "communicative practice" (and we may surmise that this is not only the case for sociological journals) (Hirschauer 2010, p. 76). He puts it like this:

\footnotetext{
What referees write is 'not what they think' (whatever that may be) but what they communicate to certain addressees, in certain forms of language. Only in this way can we recognize the limits of use of quality criteria (for example, originality: Guetzkow et al. 2004); they are without doubt orientation points for individual judgments, but they cannot do away with chronic uncertainty, because they have conflicting goals: theoretical originality or methodological solidity; relevance of topic or clarity of writing; and so on. Competing criteria therefore repeatedly produce 'differences of opinion with oneself'. Moreover, criteria can surely relate conflicting opinions to many shared standards, but their mere application cannot resolve this conflict, since it is fed by their hierarchy. This is why 'criteria' are also rhetorical resources and are contaminated by strategy: they are mobilized or kept secret, emphatically maintained or downplayed (Hirschauer 2010, p. 76, italics in original).
} 
Peer reviews are important passage points for scientific knowledge. The passing of manuscripts in the peer review process lends credibility and legitimacy to the ways in which knowledge is being presented; at the same time, the authors receive credit. This, however, is not the full story about peer reviews. Peer reviews, it has been shown above, also are important to the communicative processing of manuscripts in other ways: Peer review is a guarantee that all manuscripts deemed ready for publication by scientists receive competent readership (remember, few guarantees are certain). Peer review matches authors and first readers in a more or less effective way; it serves as a first, controlled communicative response to authors' propositions and their judgments of proper scientific communication. Moreover, peer review, regulating the stream of communication from authors to potential readers, attunes the communication within stratified communities of science. Without peer review, it could be argued, scientific communication would be highly limited and, thus, there would be no community of scientists. Without peer review, standards of scientific practice would have to be enacted and managed in much more limited networks of communication, less dispersed and less connected than is contemporary science.

\section{Science as Communication and NOS}

In this last section, I shall return to the starting point of the paper: The relationship between scientific communication and NOS. Based on my presentation of three dimensions of the communicative practices of science, I wish to present features of science as communication that might be included into NOS instruction. The discussion is kept at a general level, although I, stimulated by one peer reviewer's comments, in conclusion do try to give input to specific changes to science education based on the inclusion of "science as communication" in NOS. I am fully aware that numerous attempts have been made in order to include aspects of scientific communication, such as language, argumentation, and peer-topeer learning, in the science classroom. ${ }^{6}$ Including science as communication in NOS, however, is different from using communicative aspects of science in classrooms. It entails enabling science learners and teachers to observe scientific communication as an explicit and reflexive goal of science education itself. Like other features of NOS, the role of communication in science should become a learning goal in itself, not merely a tool of learning.

It might be fruitful to recapture accepted views of NOS within the science education community in order to see where science's communicative practices might fit in. I return to Lederman (2007, pp. 833-835) who identifies seven topics to be included in NOS instructions:

1. The difference between observation and inference: Understanding the difference between direct, sensory-based descriptions of natural phenomena and higher-order inferences and explanations.

2. The difference between laws and theories: Laws pertain to relations between observational statements, while theories are inferred explanations for observable phenomena.

3. Science is creative and innovative.

4. Scientific knowledge is theory-laden.

\footnotetext{
${ }^{6}$ See for example Carlsen (2007), Grace (2009), Kelly (2007), Lemke (1990) and Wellington and Osborne (2001).
} 
5. Science is part of human culture: It affects and is affected by non-scientific elements of the culture in which it is embedded.

6. Scientific knowledge is tentative.

7. NOS is closely affiliated with scientific inquiry, but not the same: In contrast to inquiry-based science education, NOS instruction is not about applying the methods of science; it rather aims at providing science learners with explicit and reflective views on what constitutes scientific knowledge.

I see two ways of adding communicative dimensions of science to this list (or any other similar list of NOS): Either simply by adding scientific communication as an eight item, or by trying to identify ways in which communication may be seen as part of each item (or groups of items). In my final remarks, I'll make an attempt at both approaches.

My proposal for an eight item on Lederman's list is this: Science is a mode of communication that enables and sustains knowledge in certain ways. Scientific communication not only is a way of distributing knowledge, but also constitutes knowledge itself. As a knowledge-making activity, scientific practice includes many different modes of communication, such as technical language, rhetorical resources, inscription devices, peer reviews, etc. Communication among scientists is what makes knowledge possible; it enables social and semiotic structures to emerge; and it allows for the accumulation, perpetuation, and solidification of epistemic structures tied to communicative relationships. Without communication, there would be no science, as Abelson (1980, p. 60) put it. This maxim is true on a mundane level: Science as social practice has to have communication. Without communication, there would be no sharing and no meaning of information. But it is also true in a more fundamental sense: Communication is what allows natural phenomena "to pass from the plane of external pushing and pulling to that of revealing themselves to man, and thereby to themselves" (Dewey 1925, p. 138). Scientific communication brings about and extends knowledge, while also tying scientists together in communities of inquirers.

In trying to fit communication into each of the eight items on Lederman's list, I would like to group them together like this:

- $1+2+3$ : Language for scientific purposes is technical and systematic; yet at the same time, productive and creative. Language can be used to describe natural phenomena, and it also enables higher-level, non-observational statements. By expanding nominal groups and technical taxonomies, some of which can be construed as direct observations, and by allowing for complex linguistic interrelations to emerge, science makes possible a gradual shift (and not a leap) from observation to explanation. The flexibility of linguistic transformations and the adoption of (new) literary techniques allow us to see knowledge-making as a conservative and modest endeavor and as knowledge-making as innovation and creative speculation.

- 4 + 6: Communication amongst scientists is an ongoing process, in which decisions about relevant topics for further scientific inquiry and about modes of communication all the time have to be made. Front-line research, the powerhouse of scientific knowledge-making, involves lab conversations, fiddling with instruments to produce the best inscriptions, negotiating authorship, conference discussions, and, ultimately, the process of peer review and publication/rejection. These modes of communication, and many more that are not treated in this paper, all take into consideration (parts of) existing scientific discourse and, thus, fundamentally are theory-laden. In other words, and more broadly, scientific communication is "communication-laden". Put simply, scientists engage in communication on the basis of previous communications; their 
communication also, necessarily, entails selecting what is pertinent to communicate about and what are the rhetorically useful modes of communication. As hinted at in Sect. 2, this is where the tentativeness of science comes into the picture. Decisions about the topic and resources of ongoing scientific communication involves distinguishing between what Bruno Latour (1987, p. 4) calls "ready-made science", that is, stabilized scientific knowledge in textbooks, and "science-in-the-making", that is, scientific knowledge discussed and negotiated in labs, peer reviews, etc. The implication that there is a close connection between the content and the media of (more or less tentative) scientific knowledge is important to our purposes: It is essential for science learners to realize that, despite the appeals to (absolute) objectivity and universality, scientific knowledge does not exist in and of itself; its tentativeness, or its degree of existence, to put it the Latourian way, depends on the ways in which it is involved in scientific communication. The more entangled in the communicative structures of science, the less tentative scientific knowledge becomes. In the classroom, the degree of tentativeness of scientific knowledge should be careful linked to the level, extent, and conditions of its communication.

- 5: The question about the inclusion of science in human culture becomes relatively easy to tackle in the light of scientific communication. Since communication clearly is a cultural phenomenon that has a social history and a technical side to it, communication in the sciences should be easily conveyed to science learners as both culture and technology. Moreover, understanding science as communication is one way in which to align scientific practices with other socio-technical practices, see for example Luhmann (1995, 2002). The culture of science is partly defined by its own distinctive communicative structures and codes, and, among other things, the scientific culture is tied to other parts of culture through communication. One good example of the cultural connectivity between scientific communication and other communicative domains of culture is popular science (also mentioned in Sect. 1). The historiography of popular science considers popular science as integral to the history of science proper, see for example Topham et al. (2009). The difference between science and popular science is constitutive to science, that is, making a boundary between what is real science and what is popular science is a way in which to distinguish science from other forms of cultural communication. Taking on the question about science's place in culture, at least from a historical and communicative perspective, also involves dealing with matters pertaining to the very essence of science.

- 7: I am not sure that the similarities and/or differences between scientific inquiry and NOS come out more clearly when (if) one includes scientific communication in NOS. As hinted at above, there is a parallel difference between using communicative practices of science in classrooms and making those practices knowledgeable to science learners. The difference is this: Either you do science or you talk about doing science. Either you communicate about natural phenomena using the communication tools of science, or you communicate about scientific communication. That said, I do think that scientific communication is a well-suited media for observing such differences. For example, following Luhmann (2002), one could point to one of the codes of science, namely the distinction between true and false, as what scientists aim at when they communicate with each other. This is scientific communication in action. The communicative code of NOS is different, as I see it. It observes science in a multidimensional and flexible framework with the aim of making science learners explicit and reflexive about features of scientific practice. Communicating about science along the lines of NOS, thus, is different from communicating scientifically about natural 
phenomena. And stressing communication as constitutive to science may be one way in which to pay attention to this difference.

In Sect. 2, it was suggested that NOS, having inherited the idea of science as practice and culture from science studies, also had to accept one of the fundamental tensions of science studies: The intricate relationship between local practices and universal method, between situated epistemic cultures and objective knowledge-making (Knorr-Cetina 1999). The notion of scientific communication was presented as one way of reducing this particular impediment to mundane and minute communicative interactions amongst scientists. The very idea of NOS and its application to science instruction also could have this effect. In many ways, NOS instruction attempts to demystify what scientists and science teachers mean when they talk, in a more or less empathizing way, about scientific knowledge. NOS perhaps needs to take that task more seriously by engaging in more sustained reflections about some of the inherent ambiguities of NOS and ways in which to do them away.

NOS instruction, therefore, needs to translate the topic of "science as communicative practice" into changes to curricula, learning outcomes and assessment tools. Like other NOS topics, science as communication should be taught explicitly, and the teaching should enable the students to identify aspects or modes of scientific communication, to describe the role(s) of communication(s) in science, and, at the most challenging level, to reflect upon the relationship between scientific knowledge production and scientific communication. Such learning outcomes probably are easiest and best realized in courses or classes where elements of scientific communication and/or scientific inquiry are already being used as methods of teaching. Importantly, communication amongst students should be seen as constitutive to the learning outcomes and, thus, should be included into the assessment process. It probably would be helpful if the teacher would define the means of communication to be used by the students, facilitating some kind of guided or structured communication process, or, in order to enable more open-ended communicative processes, allowed the students a greater deal of freedom in characterizing the communicative tools or process to be employed. Either way, it is crucial that the students engage in reflections about how and why they have to communicate; that they think about the way in which their communications are similar to/different from scientific communication; and that they engage in joint discussions pertaining to the extent to which communication may been conceived as a constitutive feature of scientific inquiry. This obviously needs to be fledged out at different levels of complexity and reflectivity according to the students' age and abilities, which is beyond the scope of this paper.

\section{References}

Abd-El-Khalick, F. (2005). Developing deeper understandings of nature of science: The impact of a philosophy of science course on preservice science teachers' views and instructional planning. International Journal of Science Education, 27(1), 15-42.

Abd-El-Khalick, F., Bell, R. L., \& Lederman, N. G. (1998). The nature of science and instructional practice: Making the unnatural natural. Science Education, 82(4), 417-436.

Abd-El-Khalick, F., \& Lederman, N. G. (2000). Improving science teachers' conceptions of nature of science: A critical review of the literature. International Journal of Science Education, 22(7), 665-701.

Abelson, P. H. (1980). Scientific communication. Science, 209(4452), 60-62.

Bauer, M. W., Allum, N., \& Miller, S. (2007). What can we learn from 25 years of PUS survey research? Liberating and expanding the agenda. Public Understanding of Science, 16(1), 79-95.

Bazerman, C. (1988). Shaping written knowledge: The genre and activity of the experimental article in science. Madison, WI: University of Wisconsin Press. 
Bensaude-Vincent, B. (2009). A historical perspective on science and its "others". Isis, 100(2), 359-368. Biagioli, M., \& Galison, P. (Eds.). (2003). Scientific authorship: Credit and intellectual property in science. New York: Routledge.

Bloor, D. (1999). Anti-Latour. Studies in history and philosophy of science, 30A(1), 81-112.

Bourdieu, P. (1975). The specificity of the scientific field and the social conditions of the progress of reason. Social Science Information, 14(6), 19-47.

Brown, C. (2003). The changing face of scientific discourse: Analysis of genomic and proteomic database usage and acceptance. Journal of the American Society for Information Science and Technology, 54(10), 926-938.

Bucchi, M. (2008). Of deficits, deviations and dialogues. In M. Bucchi \& B. Trench (Eds.), Handbook of public communication of science and technology (pp. 57-76). London: Routledge.

Carlsen, W. S. (2007). Language and science learning. In S. K. Abell \& N. G. Lederman (Eds.), Handbook of research on science education (pp. 57-73). Mahwah: Lawrence Erlbaum Ass.

Coady, C. A. J. (1992). Testimony: A philosophical study. Oxford: Clarendon Press.

de Solla Price, D. (1963). Little science, big science. New York: Columbia University Press.

Dewey, J. (1925). Experience and nature. Chicago: Open Court.

Duschl, R. A., \& Grandy, R. E. (2008). Reconsidering the character and role of inquiry in school science: Framing the debates. In R. A. Duschl \& R. E. Grandy (Eds.), Teaching scientific inquiry: Recommendations for research and implementation (pp. 1-37). Amsterdam: Sense Publishers.

Galison, P. (1997). Image and logic: A material culture of microphysics. Chicago: University of Chicago Press.

Galison, P. (2003). The collective author. In M. Biagioli \& P. Galison (Eds.), Scientific authorship: Credit and intellectual property in science (pp. 325-355). New York: Routledge.

Galison, P., \& Hevly, B. W. (Eds.). (1992). Big science: The growth of large-scale research. Stanford: Stanford University Press.

Garfinkel, H. (1967). Studies in ethnomethodology. Englewood Cliffs: Prentice-Hall.

Gilbert, G. N., \& Mulkay, M. J. (1984). Opening Pandora's box: A sociological analysis of scientists' discourse. Cambridge: Cambridge University Press.

Goldacre, B. (2009). Peer review is flawed but the best we've got. The Guardian. http://www.guardian. co.uk/commentisfree/2009/sep/12/bad-science-peer-review-goldacre. Assessed April 30, 2012.

Grace, M. (2009). Developing high quality decision-making discussions about biological conservation in a normal classroom setting [Article]. International Journal of Science Education, 31(4), 551-570.

Gregory, J., \& Miller, S. (1998). Science in public: Communication, culture, and credibility. Cambridge: Perseus Publishing.

Gross, A. G. (1990). The rhetoric of science. Cambridge, MA: Harvard University Press.

Gross, A. G. (2006). Starring the text: The place of rhetoric in science studies. Carbondale: Southern Illinois University Press.

Gross, A. G., Harmon, J., \& Reidy, M. (2002). Communicating science. Oxford: Oxford University Press.

Guetzkow, J., Lamont, M., \& Mallard, G. (2004). What is originality in the humanities and the social sciences? American Sociological Review, 69(2), 190-212.

Gunnarsdottir, K. (2005). Scientific journal publications: On the role of electronic preprint exchange in the distribution of scientific literature. Social Studies of Science, 35(4), 549-579.

Hagstrom, W. O. (1965). The scientific community. New York: Basic Books.

Halliday, M. A. K. (1979). Language as social semiotic: The social interpretation of language and meaning. London: Edward Arnold.

Halliday, M. A. K. (2004). The language of science. London: Continuum.

Halliday, M. A. K., \& Martin, J. R. (1996). Writing science: Literacy and discursive power. London: Falmer Press.

Hardwig, J. (1991). The role of trust in knowledge. Journal of Philosophy, 88(12), 693-708.

Harnad, S. (1997). Learned inquiry and the net: The role of peer review, peer commentary and copyright. Antiquity, 71(274), 1042-1048.

Harnad, S. (1998). Learned inquiry and the net: The role of peer review, peer commentary and copyright. Learned Publishing, 11(4), 283-292.

Hirschauer, S. (2010). Editorial judgments: A praxeology of 'voting' in peer review. Social Studies of Science, 40(1), 71-103.

Irwin, A., \& Wynne, B. (Eds.). (1996). Misunderstanding science? The public reconstruction of science and technology. Cambridge: Cambridge University Press.

Jasanoff, S. (2004). States of knowledge: The co-production of science and social order. London: Routledge. 
Keith, W., \& Rehg, W. (2008). Argumentation in science: The cross-fertilization of argumentation theory and science studies. In E. J. Hackett, O. Amsterdamska, M. Lynch, \& J. Wajcman (Eds.), The handbook of science and technology studies (pp. 211-239). Cambridge, MA: MIT Press.

Kelly, G. J. (2007). Discourse in science classrooms. In S. K. Abell \& N. G. Lederman (Eds.), Handbook of research on science education (pp. 393-442). Mahwah: Lawrence Erlbaum Ass.

Knorr-Cetina, K. (1999). Epistemic cultures: How the sciences make knowledge. Cambridge, MA: Harvard University Press.

Kuhn, T. S. (1962). The structure of scientific revolutions. Chicago: The University of Chicago Press.

Kuhn, T. S. (1970). The structure of scientific revolutions, (2nd ed.), enlarged. Chicago: University of Chicago Press.

Kusch, M. (2002). Knowledge by agreement: The programme of communitarian epistemology. Oxford: Clarendon Press.

Latour, B. (1987). Science in action. Cambridge, MA: Harvard University Press.

Latour, B. (1999a). For David Bloor... and beyond: A reply to David Bloor's 'Anti-Latour'. Studies in History and Philosophy of Science, 30A(1), 113-129.

Latour, B. (1999b). Pandora's hope: Essays on the reality of science studies. Cambridge, MA: Harvard University Press.

Latour, B. (2005). Reassembling the social: An introduction to actor-network theory. Oxford: Oxford University Press.

Latour, B. (2008). A textbook case revisited: Knowledge as a mode of existence. In E. J. Hackett, O. Amsterdamska, M. Lynch, \& J. Wajcman (Eds.), The handbook of science and technology studies (pp. 83-112). Cambridge, MA: MIT Press.

Latour, B., \& Woolgar, S. (1986). Laboratory life: The construction of scientific facts (2nd ed.). Princeton: Princeton University Press.

Lavarnd. (2011). LavaRnd. http://www.lavarnd.org/. Assessed April 30, 2012.

Lederman, N. G. (2007). Nature of science: Past, present, and future. In S. K. Abell \& N. G. Lederman (Eds.), Handbook of research on science education (pp. 831-879). Mahwah: Lawrence Erlbaum.

Lemke, J. L. (1990). Talking science: Language, learning, and values. Norwood: Ablex Publishing.

Luhmann, N. (1995). Social systems. Stanford: Standford University Press.

Luhmann, N. (2002). Die Wissenschaft der Gesellschaft. Darmstadt: Wissenschaftliche Buchgesellschaft.

Lynch, M. (1985). Art and artifact in laboratory science: A study of shop work and shop talk in a research laboratory. London: Routledge \& Kegan Paul.

Martin, J. R., \& Veel, R. (1998). Reading science: Critical and functional perspectives on discourses of science. London: Routledge.

McComas, W. F. (1998). The nature of science in science education: Rationales and strategies. Boston: Kluwer Academic Publishers.

Merton, R. K. (1973). The sociology of science: Theoretical and empirical investigations. Chicago: University of Chicago Press.

Mirowski, P., \& Sent, E.-M. (2007). The commercialization of science and the response of STS. In E. J. Hackett, O. Amsterdamska, M. Lynch, \& J. Wajcman (Eds.), The handbook of science and technology studies (pp. 635-689). Cambridge, MA: MIT Press.

Myers, G. (1990). Writing biology: Texts in the social construction of scientific knowledge. Madison: University of Wisconsin Press.

Osborne, J., Collins, S., Ratcliffe, M., Millar, R., \& Duschl, R. (2003). What "ideas-about-science" should be taught in school science? A Delphi study of the expert community. Journal of Research in Science Teaching, 40(7), 692-720.

Pinch, T. (2010). On making infrastructure visible: Putting the non-humans to rights. Cambridge Journal of Economics, 34(1), 77-89.

Radder, H. (Ed.). (2010). The commodification of academic research: Science and the modern university. Pittsburgh: University of Pittsburgh Press.

RAND Corporation. (1955). A million random digits with 100,000 normal deviates. New York: The Free Press, Collier-MacMillan.

Secord, J. A. (2004). Knowledge in transit. Isis, 95(4), 654-672.

Shapin, S. (1984). Pump and circumstance: Robert Boyle's literary technology. Social Studies of Science, 14(4), 481-520.

Shapin, S. (1995). Here and everywhere: Sociology of scientific knowledge. Annual Review of Sociology, $21,289-321$.

Shapin, S. (1996). The scientific revolution. Chicago: The University of Chicago Press.

Shapin, S. (2008). The scientific life: A moral history of a late modern vocation. Chicago: University of Chicago Press. 
Shapin, S. (2010). Never pure: Historical studies of science as if it was produced by people with bodies, situated in time, space, culture, and society, and struggling for credibility and authority. Baltimore: Johns Hopkins University Press.

Topham, J., Daum, A. W., O’Connor, R., Pandora, K., \& Bensaude-Vincent, B. (2009). Focus: Historicizing "popular science". Isis, 100(2), 310-368.

Wellington, J. J., \& Osborne, J. (2001). Language and literacy in science education. Buckingham: Open University Press.

Whyte, K. P., \& Crease, R. P. (2010). Trust, expertise, and the philosophy of science. Synthese, 177(3), 411-425. 